\title{
INFLATION AND MONETARY POLICY IN RUSSIA IN FEBRUARY 2013
}

\author{
N.Luksha
}

In February 2013 the consumer price index made 0.6\% (as compared with 0.4\% in February 2012), which is less than in January of the current year by 0.4 p.p. In March inflation has also increased: by the results of 18 days of the month, the CPI made $0.3 \%$. As a result, the inflation rate in annual terms reached $7.3 \%$. According to the tentative estimates of the Ministry of Economic Development of Russia, in February the net outflow of capital from the country amounted to about \$6bn (against \$14-16bn from the beginning of the year).

After the January upsurge in consumer prices, in February inflation has expressly slowed down: within the month the CPI has decreased from 1 to $0.6 \%$, having exceeded the similar indicator of $2012(+0.4 \%)$. As a result, inflation in annual terms has accelerated by 0.2 p.p. to $7.3 \%$ (Fig. 1). The core inflation ${ }^{1}$ in February 2013 made like in the same month last year, $0.4 \%$ (against $+0.5 \%$ in January 2013).

The CPI reduction was urged primarily by the slowdown in the growth rate of the price of food products by 2.3 times (from $1.8 \%$ in January to $0.8 \%$ in February). The reasons for this were the decrease in the growth rate of prices for fruit and vegetables (from 7.4 to 2.8\%) and alcohol (from 4.9 to $2 \%)$ and lower prices for meat and poultry (- $0.9 \%)$, sugar $(-0.3 \%)$ and eggs $(-0.6 \%)$.

The rate of increase in prices and tariffs for commercial services in February after January upgrading to 0.2 p.p. has returned to the December level (+0.4\%). At the same time, it should be recalled that in February 2012 the tariffs for commercial services were not growing. Like in January, the leaders of the increased costs were passenger transport tariffs, prices for which have grown by $0.8 \%$ : significantly increased were the rates for tickets in long-distance trains, as well as public transport tariffs. The abnormally warm February urged a decreased cost for heating.

In February the growth rate of non-food items prices remained unchanged as compared with January, having reached within the month $0.4 \%$ (vs. $0.3 \%$ in February 2012). There was noticed a growth in prices for tobacco products $(+2.4 \%)$, medicines $(+1 \%)$ and gasoline $(+0.9 \%)$. The only goods that became cheaper in February were audio and video devices (-0.4\%).

As of 18 days of March, the CPI made $0.3 \%$. As a result, the cumulative inflation from the beginning of the year reached $1.8 \%$, which is 1.5 times higher than in the same period of 2012 . The inflation rate in annual terms on March 18 remained at the level of $7.3 \%$.

The stable core inflation indicates that the overall inflation in the country is of monetary nature. Its main factors are rising foodstuffs prices due to the low monetary base effect and seasonal factors, increased duties on excisable goods and tariffs for transportation services at the beginning of the year. Some role in rising prices was also played by the February indexation of pensions. A decrease of the consumer prices inflation can be expected not earlier than in Q3 of this year, but the situation with harvest will be important. Inflationary factors

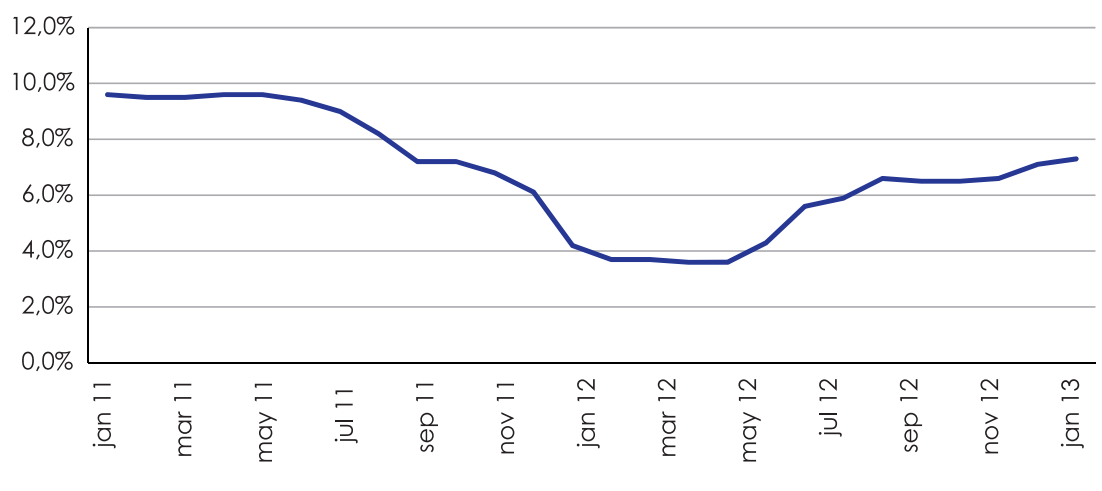

Source: RF Statistical Service.

Fig. 1.The Growth Rate of the CPI in 2011-2013 (\%year to year)

1 The core consumer price index is the indicator reflecting the level of inflation in the consumer market after adjustment for the seasonal (prices of vegetable and fruit products) and administrative (regulated tariffs for certain types of services, etc.) factors, which is also calculated by the RF Statistical Service (Rosstat). 


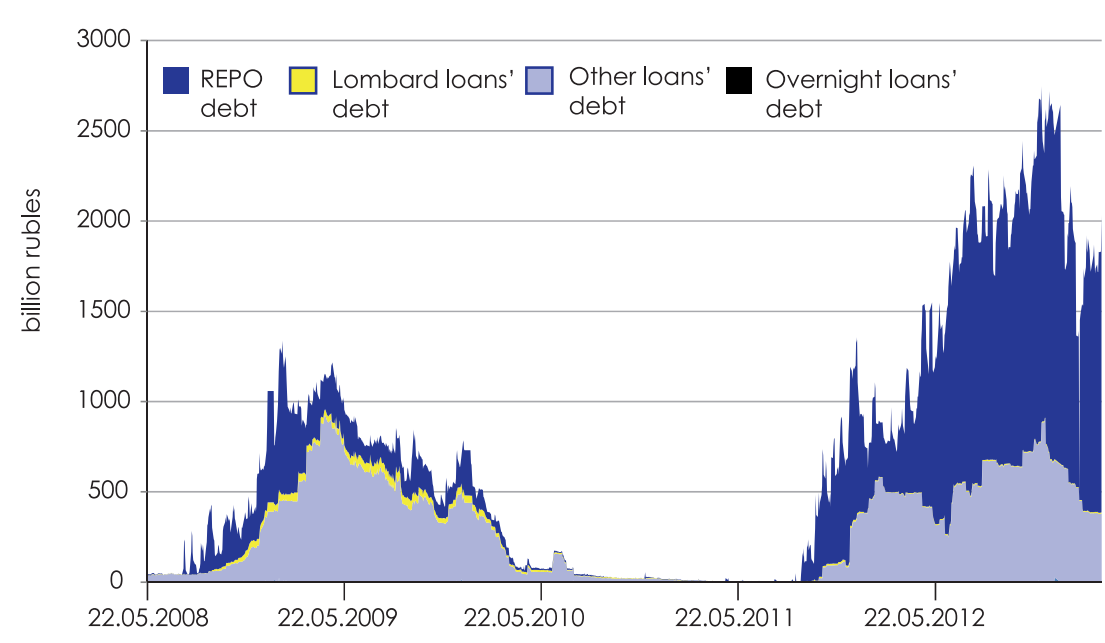

Fig. 2. Arrears of commercial banks with the Bank of Russia in 2008-2013

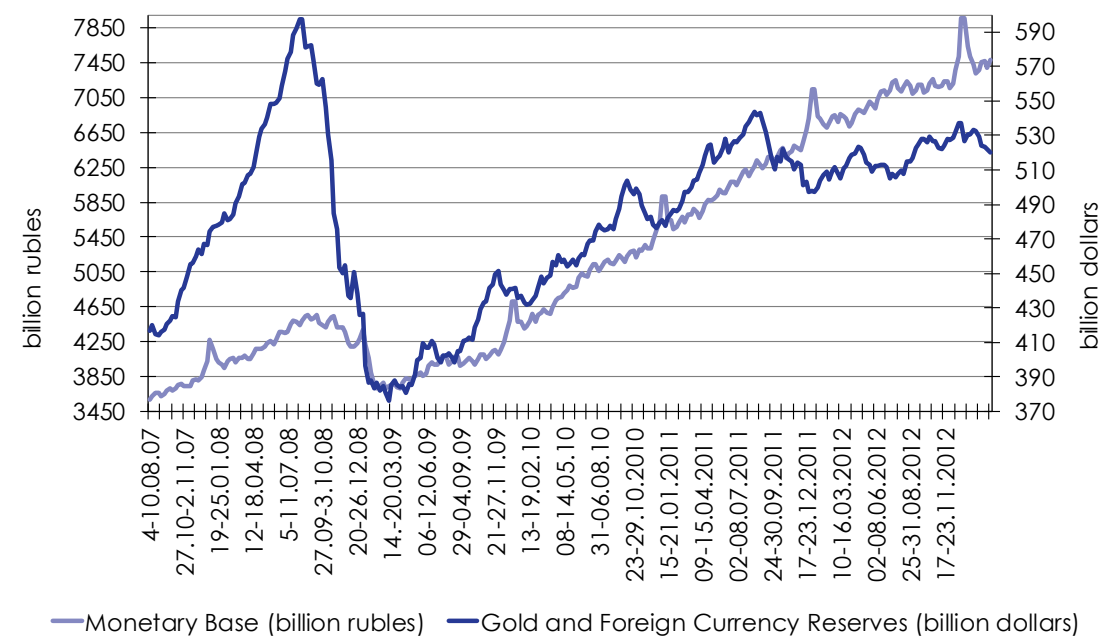

Fig. 3. Changes in the Monetary Base and in the Gold and Foreign Currency Reserves in 2007-2013

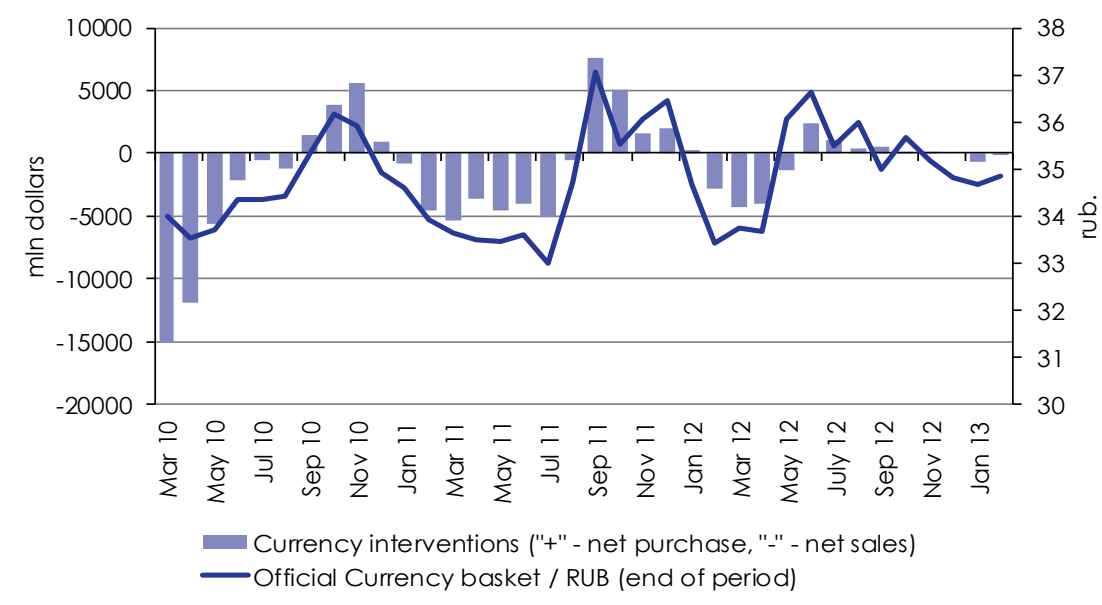

Source: RF Central Bank, author's estimates.

Fig. 4. Central Bank Currency Interventions and Dynamics of Ruble Exchange Rate in March 2010 - February 2013 can be restrained by the reduction in domestic demand and continued slowdown in monetary supply (M2 growth rate in annual terms has slowed down from $22.3 \%$ on February 1, 2012 to $13.2 \%$ as of February 1, 2013) .

In February 2013, after the January seasonal reduction of the monetary base in broad definition it has expanded. As of the end of the month, it has increased by $1 \%$ to $\mathrm{Rb} 8,506.7 \mathrm{bn}$. (Fig. 2). All components of the monetary base in broad definition were growing: the amount of cash in circulation with regard to cash balances of credit institutions has increased by $0.8 \%$ to $\mathrm{Rb} 7,067.7 \mathrm{bn}$, in correspondent accounts - by $0.4 \%$ to Rb $816.5 \mathrm{bn}$, deposits of banks with the Central Bank - by $11.9 \%$ to Rb $175.8 b n$, mandatory reserves - by $1.3 \%$ to Rb 446.7bn.

Simultaneous extension in the volume of cash in circulation and mandatory reserves in February led to the expansion of the monetary base in narrow definition (cash plus mandatory reserves) by 0.8\% to Rb 7,514.4bn (Fig. 3).

In February excessive reserves of commercial banks ${ }^{1}$ stopped to decrease and their volume increased within the month by $2.3 \%$ to $\mathrm{Rb} 992.3 \mathrm{bn}$. The situation in the monetary market at the beginning of the year remained relatively smooth. However, in March the situation in the monetary market started to deteriorate. This is evidenced, on the one hand, by the growth of the banks' indebtedness under repo agreements (in March it returned nearly $\mathrm{Rb} 1.5$ trillion (Fig. 2), and on the other hand, by the increase in interbank rates above $6 \%$ (reference rate of Mosprime in March made 6.1-6.4\%).

In mid-March 2013 the volume of international reserves of the Central Bank of Russia has

1 Under the excessive reserves of commercial banks with the RF Central Bank is understood the sum of correspondent accounts of commercial banks, their deposits with the RF CB and the RF CB bonds of commercial banks. 
reached the six-month minimum of $\$ 520 \mathrm{bn}$, having decreased from the beginning of the year by $3.2 \%$. Reduction of the Russian international reserves in dollar terms is due to the strengthening of the U.S. dollar against the Euro because of Cyprus problems in economy.

However, the volume of foreign exchange interventions of the RF Central Bank remained insignificant in February. Net purchases of foreign currency by the Bank of Russia amounted to $\$ 118.96 \mathrm{~m}$ (which is 5 times lower than in January) and Euro 24.68m (two times lower than in January) (Fig. 4).

In January of this year, according to the tentative estimates of the Ministry of Economic Development of Russia, the net outflow of capital amounted to about $\$ 6 \mathrm{bn}$. Therefore, in the first two months of this year, it reached $\$ 14-16 \mathrm{bn}$, which makes nearly half of the amount in the same period of 2012, when the outflow reached $\$ 27.8 \mathrm{bn}$ (Fig.4).

For the first three weeks of March the U.S. currency has grown by $1 \%$ to Rb 30.94. European currency, however, has decreased by $0.4 \%$ to $\mathrm{Rb} 39.88$. As a result, the cost of the two-currency basket slightly increased, amounting to $\mathrm{Rb} 34.96$ on March 21 (+0.3\%).

The major global macroeconomic event in March was the situation in Cyprus, namely its negotiations with Russia and three international creditors - the European Commission, the ECB and the IMF - on a possibility of a loan under condition of a lumpsum tax on bank deposits. In view of Cyprus situation, Euro has declined in the world market: on March 19 it dropped to the indicator of Euro/\$ 1.28. A decrease in the credit rating of Italy has also affected the Euro rate. 